\title{
METHOD FOR CONTROLLING MELIORATIVE TECHNOLOGIES ON SLOPING CULTIVATED LANDS USING LARGE SCALE PROFILOMETER
}

\author{
Sergey Vasiliev, Alexander Kirillov, Irina Afanasieva \\ Chuvash State Pedagogical University named after I. Y. Yakovlev, Russia \\ vsa_21@mail.ru,kan80@mail.ru, irinka1783@mail.ru
}

\begin{abstract}
Many approaches to the evaluation of erosion technologies have been developed, but not all of them correspond to the reality of the processes that are taking place. The observed discrepancy is most likely due to insufficient consideration of soil parameters. These parameters on the sloping cultivated lands vary significantly and the slope drain hydraulics have their own principal features compared, for example, to river processes. The work substantiates the constructive-technological parameters of profilographs for controlling meliorative technologies on sloping cultivated lands. Identified certain difficulties in the design, implementation and operation of land meliorative activities are often associated with significant spatial and temporal variability of the main parameters of the underlying surface. It is proposed to use the method of determining the average slope by profilography of the tested underlying soil surface to determine these parameters. To implement this method, it is proposed to use a profilograph equipped with an encoder and a position sensor. As a result of the research, the direction and magnitude of the average soil surface slope of the field elementary section is determined, as well as the roughness and waviness of the treated soil surface. The diameter of the scanned circle is substantiated depending on the applied meliorative technology on the sloping cultivated lands as the main constructivetechnological parameter of the profilograph. Based on the results of theoretical studies, the dependence of the number of intersections with the midline on the scanned circle diameter and the width of the technological groove were obtained. The obtained dependence made it possible to calculate the recommended scanning radius of the soil surface by a profilograph for various soil-cultivating and anti-erosion machines, taking into account the microrelief or the crest of the soil after its treatment. The results of the theoretical studies are obtained from the test reports of the anti-erosion machines provided by the machine-testing stations on the sites of the MIS organizations and are presented in tables.
\end{abstract}

Keywords: profiling of the soil surface, profilograph, substantiation of parameters, underlying surface, technical means of control, scanned circle.

\section{Introduction}

Special attention was given to the problem of surface flow retention. While solving it, it is possible to manage the drainage and soil erosion processes during the introduction and control of antierosion technologies on sloping cultivated lands. Many approaches to the evaluation of erosion technologies have been developed, but not all of them correspond to the reality of the processes that are taking place. The observed discrepancy is most likely due to insufficient consideration of soil parameters. These parameters on the sloping cultivated lands vary significantly, and the hydraulics of the slope drain have their own principal features compared, for example, to river processes. Thus, certain difficulties arise in the scientific, methodological and technical plan.

Certain difficulties that arise in the design, implementation and operation of land meliorative activities on the sloping cultivated lands are often associated with significant spatial and temporal variability of the basic parameters of the underlying surface: the average slope, ripple and roughness [1-3].

A method for determining the average slope [4] and other parameters of the underlying surface at the elementary site in the field conditions and the technical means of control for its implementation, taking into account the works [5-8], have been developed for conducting experimental studies on sloping lands.

\section{Materials and methods}

To carry out agrotechnical evaluation of land meliorative activities on sloping cultivated lands, we propose to use a profilograph, a schematic diagram of its construction is shown in Fig. 1.

The device consists of a massive base with rods 1 for fixing on the soil surface, on which the axle 2 is mounted with the help of the bearing, in the lower part of which the encoder (angle sensor 3) is fastened, and in the upper part a movable shoulder 4 with a counterweight 5 on one side and a laser position sensor 6 on the other side, installed with the help of the rod 7, which allows to change the 
initial position of the laser sensor 6 . In the upper part of the axis 2 , an electronic signal processing unit 8 is installed, which is connected via a USB cable to the laptop 9. The axis 2 also attaches the level 10.

The device functions as follows. Previously, the profilograph is installed strictly vertically on the level 10 in all directions, moving the shoulder 4 along the circumference. The electric power for the angle and position sensors is fed from the laptop 9. The computer program "RF $605+$ encoder" is started on the laptop 9.

Then the shoulder 4 slowly rotates around the base 1 . In one turn, the laser position sensor 6 scans the soil surface and transmits information to the electronic signal processing unit 8 . The principle of optical triangulation is based on the operation of the laser position sensor. The radiation from a semiconductor laser is focused by the lens on the soil. Scattered on the soil, the radiation is collected on a CCD-ruler. The signal processor calculates the distance to the object from the position of the light spot image on the ruler.

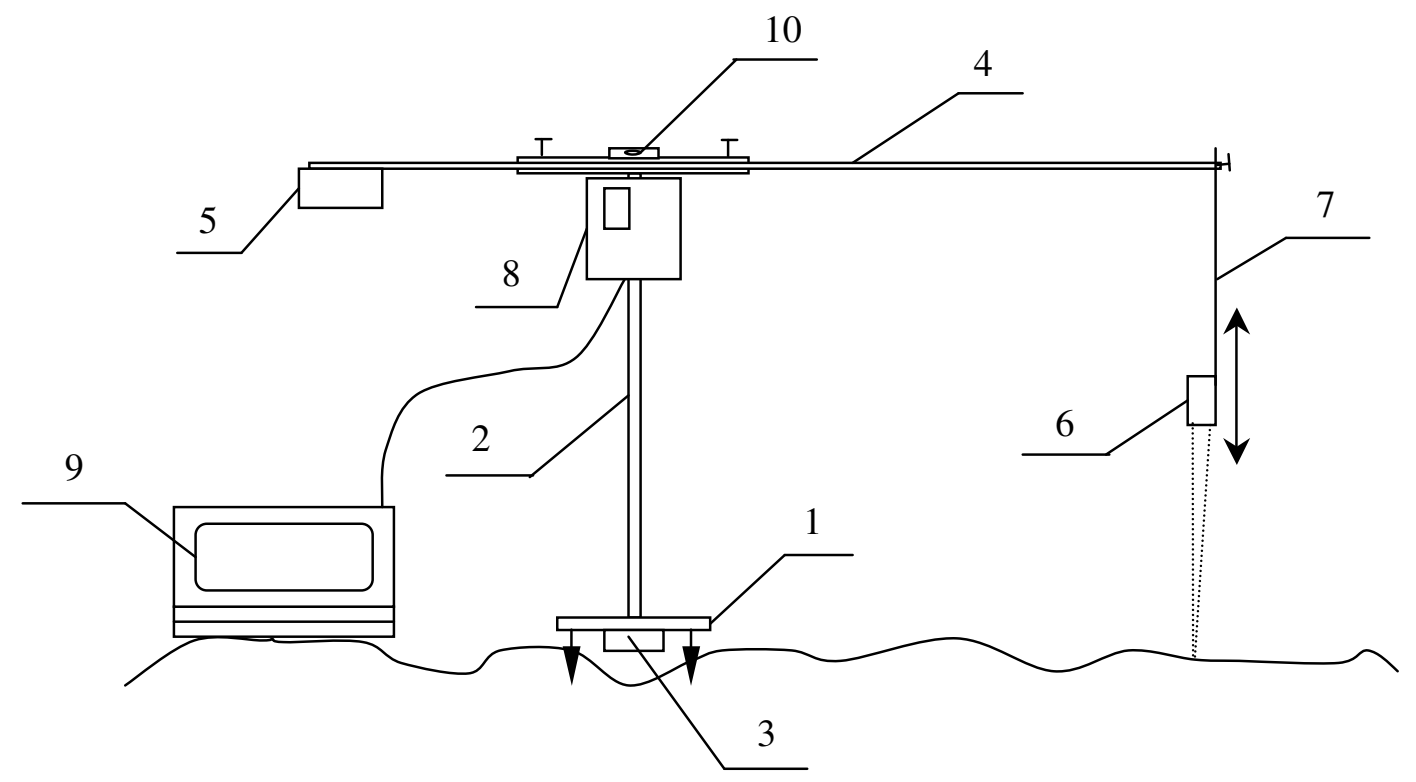

Fig. 1. Schematic diagram of profilograph design

At the same time, the encoder 3 measures the position of the axis 2 relative to the base 1 and also forwards the instantaneous values of the rotation angle to the electronic signal processing unit 8 .

Thus, two signals are simultaneously sent to the electronic signal processing unit, which are transferred to the laptop 9 after processing. The computer program allows to present information in polar coordinates for 2 parameters: the distance between the position sensor and the soil surface, and also the angle of rotation corresponding to this position from the zero mark.

Use of a profilograph on the slope. First, relief lines are calculated on the digital map. The lines are perpendicular to the slope horizontals and coincide with the direction of the water flow. The established lines are processed by the approximation of splines that are perpendicular to the spline functions of the slope contours. The resulting coordinate system is two mutually orthogonal trajectories of the curves. Then, the section curves are determined between the lines of the largest slope which can be defined by equidistant spline functions [3].

Justification of the diameter of the scanned circle depending on the applied meliorative technology on the sloping cultivated lands as the main design and technological parameter of the profilograph will be carried out using the design scheme in Fig. 2.

For the tested area, let us define two scanned circles with diameters $D_{1}$ and $D_{2}$ for the profilograph.

Let us define the length of the scanned circles:

$$
\begin{aligned}
& L_{1}=2 \pi R_{1}=\pi D_{1}, \\
& L_{2}=2 \pi R_{2}=\pi D_{2},
\end{aligned}
$$


where $\quad R_{1}$ and $R_{2}$ - the radii of the scanned circles on the soil surface.

It is known that at the base length of the measurement the number of intersections of the profile with the middle line should reach 40-50 times [9].

Proceeding from this, we determine the number of intersections of the profile with the middle line for the tested area:

$$
n=\frac{D}{b},
$$

where $n$-number of intersections with the middle line in the tested area;

$b$ - width of the technological furrows for a specific soil tillage operation.

\section{Results and discussion}

Using the formula (3), let us graphically represent the dependence of the number of intersections with the midline on the diameter of the scanned circle and the width of the furrow (Fig. 3). The width of the technological furrow that is characteristic for presowing tillage and sowing is set from 3 to $15 \mathrm{~cm}[10]$.

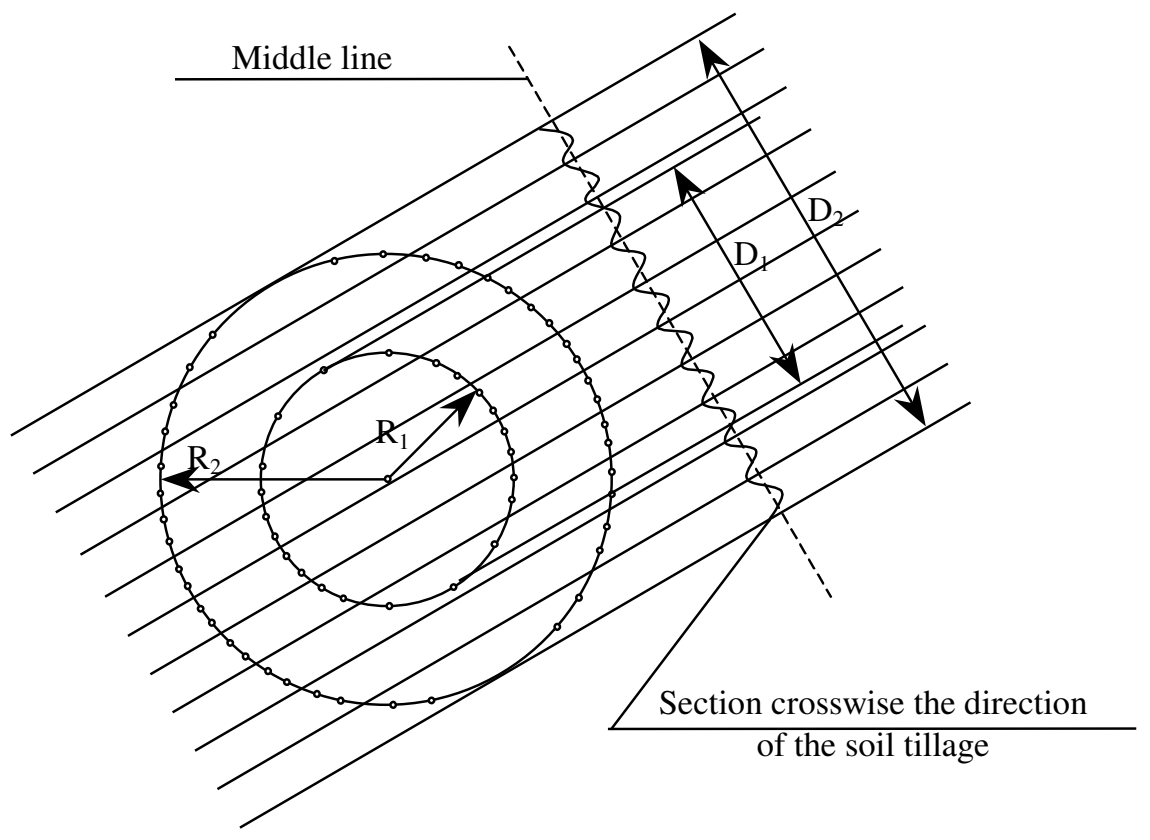

Fig. 2. Scheme to justify diameter of scanned circle

In reality, the clods sliding down to the bottom during the main and presowing tillage change the "ideal" drainage surface. Thus, the number of intersections with the middle line increases, and there is no need to significantly increase the radius, which may entail a decrease in the accuracy of the studies for the tested elementary area. This phenomenon is noted on the graph by increasing the field width for each given size of the technological furrow (see Fig. 3).

Using the graphical dependence of the change in the number of intersections with the midline of the scanned circle diameter and the width of the technological furrow, obtained from formula (3), and also taking into account the microrelief or the ridiculation of the soil after its tillage, the recommended radius of scanning the soil surface by a profilograph for various tillage and erosion machines is obtained (Table 1).

The data for the theoretical study are obtained from the test reports of the anti-erosion machines using provided by the machine testing stations on the sites of the MIS organizations.

Analysis of the table shows that predominantly pre-sowing and autumn-growing soil cultivation creates a microrelief on the soil surface within 1.8-3.5 mm, and the main and erosion control of the soil form an essential ridging - up to $10 \mathrm{~cm}$ and more. 


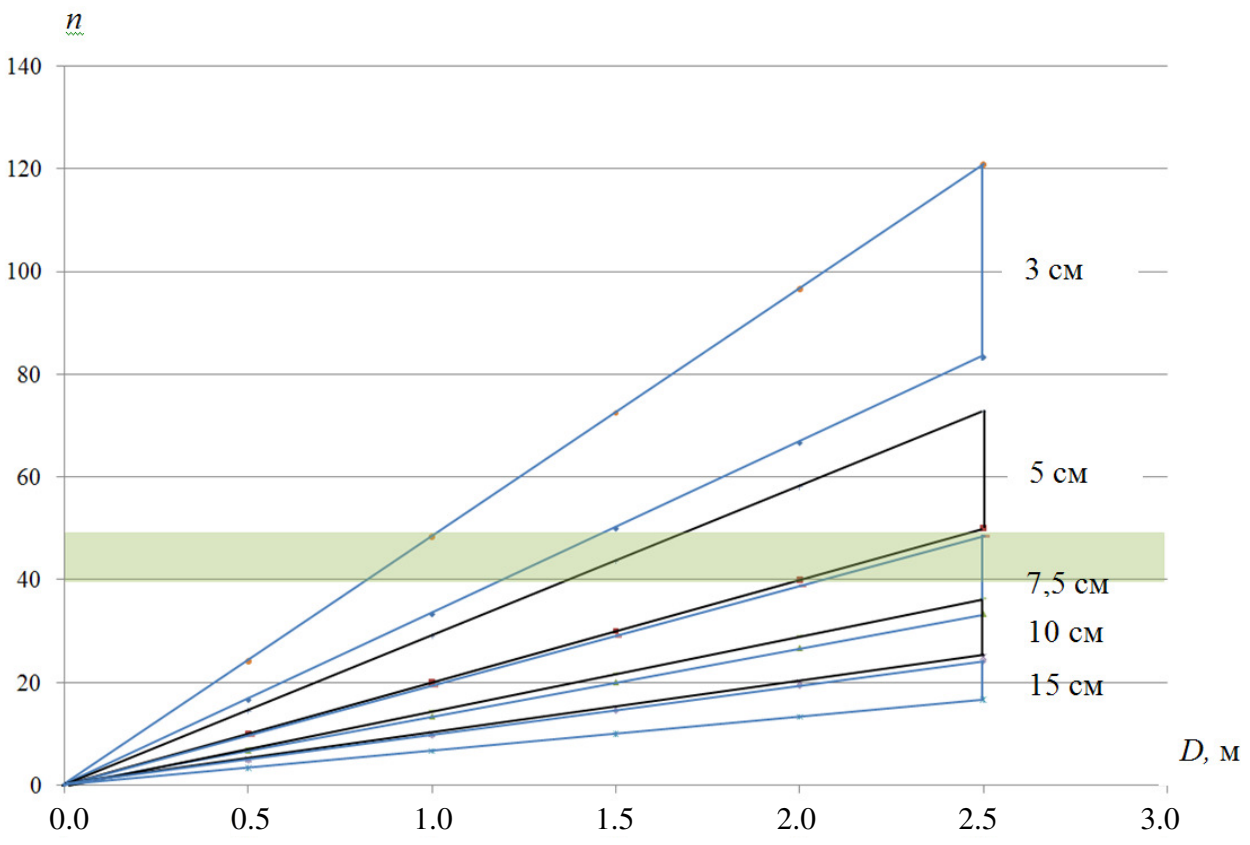

Fig. 3. Dependence of intersections number with midline on diameter of scanned circle and width of technological furrow

For the experiments, we used sod-podzolic light loamy soil of the Vurnar district of the Chuvash Republic. The color of the soil is light gray. It is infertile [1], and it is formed on loam. After watering, it becomes strongly compacted and covers with crust. The soil becomes impermeable to water and air (bulk weight is $1.62 \mathrm{~g} \cdot \mathrm{cm}^{-3}$, solid phase density is $2.63 \mathrm{~g} \cdot \mathrm{cm}^{3}$, coefficient of filtration is $(0.05-0.44)$ $10^{-5} \mathrm{~m} \cdot \mathrm{s}^{-1}$, humus content is $1.63 \%$, specific surface area of the solid phase is $31.4 \mathrm{~m}^{2} \cdot \mathrm{g}^{-1}$, porosity is $0.451)$. The soil characteristics were determined by classical methods $[1 ; 3]$, and the specific surface area was determined by the aerodynamic method [3].

Table 1

\section{Recommended radius of soil surface scanning by a profilograph for various tillage and anti-erosion machines}

\begin{tabular}{|l|c|c|c|}
\hline Name and brand of tillage machine & Type of work & $\begin{array}{c}\text { Microrelief, } \\
\text { cm }\end{array}$ & $\begin{array}{c}\text { Scanning } \\
\text { radius, m }\end{array}$ \\
\hline Disc semi-trailer harrow BDP-4 $\times 4 \mathrm{P}$ & fall tillage & 1.8 & $0.5-0.75$ \\
\hline Cultivator K-720 MK & tillage of the steam field & $2-2.1$ & $0.75-1$ \\
\hline Disc cultivator RTS & fall surface tillage & 2.1 & $0.75-1$ \\
\hline $\begin{array}{l}\text { Single-disk hydroficated harrow } \\
\text { LDG-15 }\end{array}$ & tillage of the steam field & 2.3 & $0.75-1$ \\
\hline Chizel lift-up ripper RChN-4.5 & fall tillage & $2.3-4$ & $0.75-1$ \\
\hline Cultivator PK-990 & tillage of the steam field & 2.5 & $0.75-1$ \\
\hline Block-modular ripper-plow PRB-3 & $\begin{array}{c}\text { basic stubble tillage of } \\
\text { winter wheat }\end{array}$ & $2.8-3.2$ & $0.75-1$ \\
\hline Cultivator K-570M & presowing tillage & $2.9-3.1$ & $0.75-1$ \\
\hline $\begin{array}{l}\text { Anti-erosive combined cultivator } \\
\text { KPE-3.8G }\end{array}$ & fall tillage & $3.5-6.5$ & $0.75-1$ \\
\hline $\begin{array}{l}\text { Deep tillage cultivator "SALFORD } \\
\text { DRH 9815-19" }\end{array}$ & \begin{tabular}{c} 
basic deep soil-free tillage \\
\hline Tillage cultivator PK-850
\end{tabular} & up to 5 & $1-1.25$ \\
\hline $\begin{array}{l}\text { Chizel deep tillage cultivator-plow } \\
\text { PCh-2,5 }\end{array}$ & $\begin{array}{c}\text { deep soillage loosening by } \\
\text { stubble background }\end{array}$ & $5.2-5.4$ & $1-1.25$ \\
\hline Anti-erosion tool OP-3S & fall bottomless tillage & $6.3-11.2$ & $1.25-1.5$ \\
\hline $\begin{array}{l}\text { Deep tillage cultivator-milling chizel } \\
\text { plough GS-4M }\end{array}$ & continuous tillage & 13.6 & $1.5-1.75$ \\
\hline
\end{tabular}


The tested catchment area of the sloping cultivated lands is divided into elementary areas, which have an elongated shape along the lines of the largest slope and represent rows of linear canals. The calculated linear canal is divided into elementary sections according to the measured characteristics: the potential of erosion resistance, roughness, average slope, ripple, etc. Thus, the number of measured actions can vary significantly depending on the complexity of sloping lands. The number of points per one $\mathrm{km}^{2}$ can be reduced by the method of kriging.

Further, for the tested area, one can determine the volume or mass of washable soil per unit of time, using the expressions [1;3]. Multiplying the values obtained for a time at a constant flow rate, one can calculate the flow rate of solid slope [1].

Thus, it is possible to determine the total solid flow rate over the calculated time by the soil characteristics and conditions of anthropogenic impact. In addition, one can predict the amount of eroded soil at a given flow rate and other parameters by the area of linear canals prone to water erosion of the soil.

\section{Conclusions}

1. To control melioration technologies on sloping cultivated lands, a method is proposed for determining the average slope by profiling along the circumference of the tested underlying soil.

To implement this method, a profilograph is used.

2. The diameter of the scanned circle is substantiated depending on the applied meliorative technology on the sloping cultivated lands as the main design and technological parameter of the profilograph.

3. The dependence of the number of intersections with the midline on the diameter of the scanned circle and the width of the technological furrow is obtained.

4. The recommended radius of soil surface scanning by a profilograph for various soil-cultivating and anti-erosion machines is calculated, taking into account the microrelief or ridging of the soil after its tillage. The result is presented in the table.

5. According to the obtained data, the volume or mass of the washed soil per unit of time, the flow of solid slope, is determined using known expressions for the tested area. Thus, it is possible to determine (by the soil characteristics and conditions of anthropogenic impact) the total solid flow rate over the calculated time, the area of linear canals prone to water erosion of the soil, to predict the amount of eroded soil at a given flow rate and other parameters of sloping cultivated lands.

\section{References}

[1] Vasiliev S.A. Hydraulic roughness of slope agrolandscapes / S. A. Vasiliev, I. I. Maksimov, V. I. Maksimov. - Cheboksary : New Time, 2014, 210 p.

[2] Vasiliev S. A. The results of experimental studies of hydro-physical and erosive properties of soils on the territory of the "Trud" collective farm of the Batyrevsky district of the Chuvash Republic / S. A. Vasiliev and others // Bulletin of Chuvash State Pedagogical University named after. I. Ya. Yakovlev. - 2013. № 4 (80), Part 2. pp. 39-45.

[3] Maksimov I. I. Energy concept of erosion stability of anthropogenic agrolandscapes / I. I. Maksimov V. I. Maksimov. - Cheboksary : Chuvash State Agricultural Academy, 2006, 304 p.

[4] Patent № 2560752 of the Russian Federation. Method for determining the average slope of an elementary site in the field and a profilograph for its implementation / I. I. Maksimov, S. A. Vasiliev, V. V. Alekseev, M. A. Vasiliev and others. - Publ. 08.20.2015. Bul. № 23.

[5] Vasiliev S. A. Technique and device for profiling the soil surface and determining the direction of the flow of atmospheric precipitation in the field / S. A. Vasiliev, I. I. Maksimov, V. V. Alekseev // Bulletin of the Agroindustrial Complex of Stavropol. - 2015. - № 3 (19). pp. 22-26.

[6] Vasiliev S. A. Determination of the equivalent roughness of the fast-forming surface for the evaluation of erosion control measures on sloping lands / S. A. Vasiliev, I. I. Maksimov, V. V. Alekseev // Melioration and water management. - 2014. № 4. pp. 32-34.

[7] Vasiliev S. A. Energy approach to the estimation of the erosion-transporting capacity of the water flow on the slope agrolandscape / S. A. Vasiliev, I. I. Maksimov V. V. Alekseev // Scientific journal of the Russian Research Institute of Problems land reclamation. - 2015. - No. 3 (19). pp. 79-93. [online][11.02.2018] Available at: 
http://www.rosniipm-sm.ru/dl_files/udb_files/udb13-rec358-field6.pdf.

[8] Kireev I. M. Devices for determining the relief and microrelief of the field section / I. M. Kireev, Z. M. Koval, F. A. Zimin // Measuring technique. - № 8. 2014. pp. 24-26.

[9] Annotated collection of measuring instruments and test equipment. - Novokubansk : FGNU "RosNIIITiM", 2012, 51 p.

[10] Mishin P. V. Workshop on the operation of the machine-tractor park / P. V. Mishin, V. Kh. Khuzin. - Cheboksary, 1999, 110 p. 